\title{
Article \\ Ozonized Water Administration in Peri-Implant Mucositis Sites: A Randomized Clinical Trial
}

\author{
Andrea Butera ${ }^{1}\left(\mathbb{D}\right.$, Simone Gallo ${ }^{2, *(\mathbb{D})}$, Maurizio Pascadopoli ${ }^{2, *(\mathbb{D}}$, Gabriele Luraghi ${ }^{1}$ and Andrea Scribante $^{2, *(\mathbb{D})}$ \\ 1 Unit of Dental Hygiene, Section of Dentistry, Department of Clinical, Surgical, Diagnostic and Pediatric \\ Sciences, University of Pavia, 27100 Pavia, Italy; andrea.butera@unipv.it (A.B.); \\ gabriele.luraghi01@universitadipavia.it (G.L.) \\ 2 Unit of Orthodontics and Pediatric Dentistry, Section of Dentistry, Department of Clinical, Surgical, \\ Diagnostic and Pediatric Sciences, University of Pavia, 27100 Pavia, Italy \\ * Correspondence: simone.gallo02@universitadipavia.it (S.G.); maurizio.pascadopoli01@universitadipavia.it (M.P.); \\ andrea.scribante@unipv.it (A.S.)
}

Featured Application: Ozone therapy should be further evaluated to fully understand its efficacy for the treatment of peri-implant mucositis.

check for updates

Citation: Butera, A.; Gallo, S.; Pascadopoli, M.; Luraghi, G.; Scribante, A. Ozonized Water Administration in Peri-Implant Mucositis Sites: A Randomized Clinical Trial. Appl. Sci. 2021, 11, 7812. https://doi.org/10.3390/app11177812

Academic Editor: Antonio Scarano

Received: 9 July 2021

Accepted: 22 August 2021

Published: 25 August 2021

Publisher's Note: MDPI stays neutral with regard to jurisdictional claims in published maps and institutional affiliations.

Copyright: (c) 2021 by the authors. Licensee MDPI, Basel, Switzerland. This article is an open access article distributed under the terms and conditions of the Creative Commons Attribution (CC BY) license (https:// creativecommons.org/licenses/by/ $4.0 /)$.

\begin{abstract}
Peri-implant mucositis represents an inflammatory lesion of the mucosa surrounding an endosseous implant, without the loss of the supporting peri-implant bone. Considering its reversible nature, every effort should be made to contrast it, thus avoiding the eventual progression towards peri-implantitis. The aim of the present randomized clinical trial is to evaluate the efficacy of the ozonized water against peri-implant mucositis. A total of 26 patients diagnosed for this latter clinical condition were randomly divided according to the professional oral hygiene protocol performed on the pathological sites at baseline, at T1 (1 month), and T2 (2 months). Group 1 underwent an ozonized water administration (experimental treatment), whereas Group 2 underwent a pure water one (control treatment). Both administrations were performed with the same professional irrigator (Aquolab ${ }^{\circledR}$ professional water jet, Aquolab s.r.l. EB2C S.r.l., Milano, Italy) with no differences in color or taste between the two substances delivered. At each appointment, the following indexes were assessed: the Probing Pocket Depth (PPD), Plaque Index (PI), Bleeding on Probing (BoP), and Bleeding Score (BS). As regards intragroup differences, in Group 1 ozonized water significantly and progressively reduced all the clinical indexes tested, except for PI in the period T1-T2, whereas no significant differences occurred within the control group. Despite this, no significant intergroup differences were generally detected between the two treatments. Accordingly, the role of ozone for the management of peri-implant mucositis deserves to be further investigated.
\end{abstract}

Keywords: ozone; ozone therapy; ozonized water; peri-implant mucositis; peri-implantitis; implants; implant failure; periodontal therapy; oral hygiene; randomized clinical trial

\section{Introduction}

In recent years, the application of ozone in medicine and dentistry has particularly increased because of its several recognized benefic actions. Much research has demonstrated a broad-spectrum antimicrobial activity for ozonized water/oils against bacteria, virus, protozoa, and fungi [1-5]. Additionally, many other properties have been attributed to ozone, such as immunomodulant, anti-hypoxic, anti-inflammatory, and regenerative ones $[6,7]$.

Focusing on the applicability of ozone in dentistry, several clinical conditions have been treated by recourse to ozone therapy, e.g., the management of wound-healing, dental caries, oral lichen planus, gingivitis and periodontitis, halitosis, osteonecrosis of the jaw, post-surgical pain, plaque and biofilms, root canal treatment, dentin hypersensitivity, temporomandibular joint disorders, and teeth whitening [7-10]. Moreover, ozone is also 
used as a functionalizing agent on implant surfaces (for both dental and orthopedic use) with the goal of improving their osseointegration [11-14].

Considering the abovementioned applications, the use of ozone for the treatment of gingivitis and periodontitis appears quite promising. Gingivitis is regarded as the result of a progress accumulation on the teeth of dental plaque/calculus, which is a complex bacterial biofilm embedded into a polymeric matrix. This causes an inflammatory condition which continues in cases where proper domiciliary and professional oral hygiene procedures are not performed to remove this biofilm. Despite this condition being reversible, it may also evolve into an irreversible one (i.e., periodontitis) with the degradation of soft and hard tooth-supporting tissues and, eventually, tooth loss $[15,16]$.

Nowadays, the implant-prosthetic therapy represents the main possible resource to face a total or partial edentulism, achieving a high success rate for both the upper and the lower arch [17]. However, the gingival tissue around implants, the so-called peri-implant mucosa, does not come without the risk of developing either a reversible or an irreversible inflammation too. According to the latest Classification of Periodontal and Peri-Implant Diseases and Conditions (2017) [18], the following four states might regard peri-implant tissues: 1 , peri-implant health; 2 , peri-implant mucositis; 3 , peri-implantitis; 4 , peri-implant soft and hard tissue deficiencies.

Considering peri-implant mucositis, this condition is defined as 'an inflammatory lesion of the mucosa surrounding an endosseous implant without loss of supporting periimplant bone' [19]. On this basis, a clinical case is defined in the presence of peri-implant mucosal inflammation but in the absence of peri-implant bone loss. The main clinical sign is bleeding on gentle probing, though additional features can occur, such as erythema, swelling, and/or suppuration $[18,19]$. It has been demonstrated, both in animals and humans, that plaque is the etiological factor for peri-implant mucositis [20,21], whereas there is limited evidence for a non-plaque-induced form; despite this, however, the host response to the bacterial challenge also plays a fundamental role, and conditions such as smoking, diabetes mellitus, and radiation therapy might affect this process. As regards the resolution of peri-implant mucositis, evidence suggests that this even takes more than three weeks following the restitution of plaque/biofilm control [18].

The aim of this randomized clinical trial is to evaluate the short-term efficacy of subgingival applications of ozone water, delivered using a professional irrigator, in assuring a proactive impact for the domiciliary maintenance of peri-implant mucositis sites, with respect to a negative control (pure water). The null hypothesis of the study is that there are not any significant intergroup and intragroup differences between the two different administrations.

\section{Materials and Methods}

\subsection{Materials}

An Aquolab ${ }^{\circledR}$ professional water jet (Aquolab s.r.1. EB2C S.r.1., Milano, Italy) was used to deliver ozonized water in periodontal pockets [8]. This device is an irrigator with a magnetic drive pump that produces a continuous release of ozonized water. A $0.8 \mathrm{~mm}$ diameter nozzle was used, and the higher range of ozone tension $(12 \mathrm{~V})$ was set. According to manufacturer's indications, water level 1 and ozone level 3 were chosen, which, respectively, correspond to $75 \%$ and $100 \%$ PWM (pulse-width modulation) water pump. Water level 1 was used alone to administer pure water in the control group.

\subsection{Randomized Clinical Trial}

\subsubsection{Trial Design}

This was a parallel-group, randomized, placed controlled, and single-center trial with a 1:1 allocation ratio, approved by the Internal Review Board of the Unit of Orthodontics and Pediatric Dentistry, Section of Dentistry, of the University of Pavia, Pavia, Italy (registration number: 2021-0203) and registered on Clinicaltrials.gov (accessed on 8 July 2021) (NCT number: NCT04845087). 


\subsubsection{Participants}

Patients addressing to the Unit of Dental Hygiene, Section of Dentistry, Department of Clinical, Surgical, Diagnostic and Paediatric Sciences of the University of Pavia (Pavia, Italy) were recruited in April 2021 and the study lasted until July 2021. The informed consent of patients was collected. Both interventions and outcome assessments were conducted at the same unit.

The inclusion criteria were the following: age between 18-70 years, no smoking, no systemic diseases, history of previous periodontitis (stage II, grade B), use of electric toothbrush, presence of a fixed implant rehabilitation with at least two fixtures, and presence of peri-implant mucositis at least at one implant. Peri-implant mucositis is defined according to the latest Classification of Periodontal and Peri-Implant Diseases and Conditions (2017) [18], therefore requiring a Bleeding Score higher than 0. Conversely, the following were considered as exclusion criteria: absence of dental implants, presence of systemic diseases, and presence of cardiac pacemaker.

\subsubsection{Interventions and Outcomes}

At the first appointment (T0), patients were asked to sign the informed consent to participate to the study. After that, an instructed operator assessed the following periodontal clinical indices on each peri-implant site by means of a probe (UNC probe 15; Hu-Friedy, Chicago, IL, USA): Probing Pocket Depth (PPD) (measured on six sites per element), Bleeding on Probing (BOP), Bleeding Score (BS), and Plaque Index (PI) [15]. Then, a professional supragingival and subgingival oral hygiene was conducted using a piezoelectric instrument (Multipiezo, Mectron S.p.a, Carasco, Italy) and Gracey curettes (Hu-Friedy, Chicago, IL, USA), followed by supragingival and subgingival application of a decontaminating glycine powder (Glycine Powder, Mectron S.p.a., Carasco, Italy). At this stage, patients were randomly divided into two groups according to the treatment of the peri-implant mucositis sites: patients assigned to Group 1 (trial group) received an administration of ozonized water with the Aquolab ${ }^{\circledR}$ professional device with an angulation of 45 degrees of the nozzle and for $60 \mathrm{~s}$ time per site; conversely, patients assigned to Group 2 (control group) received the administration of pure water by means of the same device. Participants were instructed to a proper oral hygiene and underwent a 2-month follow up with appointments after 1 month (T1) and 2 months (T2) from baseline. At each appointment, the periodontal assessment with the collection of clinical indices, the decontaminating procedure with glycine powder, and the application of ozonized water or pure water were performed. The timing considered was chosen with the aim of focusing on the short-term efficacy of ozone applications for the domiciliary maintenance of peri-implant mucositis sites, and also on the basis of a previous report [22].

The protocol of the study is shown in Table 1.

Table 1. Protocol adopted for the study.

\begin{tabular}{cl}
\hline Appointment & \multicolumn{1}{c}{ Procedures } \\
\hline & - Signature to the informed consent for the study. \\
& - Assessment of periodontal clinical indexes. \\
& - Professional supragingival and subgingival oral hygiene. \\
- Supragingival and subgingival decontamination of glycine powders. & Trial Group: administration of ozonized water on peri-implant mucositis sites. \\
& Placebo Group: administration of pure water on peri-implant mucositis sites. \\
& - Assessment of periodontal clinical indexes. \\
& - Supragingival and subgingival decontamination of glycine powders. \\
After 1 month (T1) & $\begin{array}{l}\text { Trial Group: administration of ozonized water on peri-implant } \\
\text { mucositis sites. }\end{array}$ \\
& Placebo Group: administration of water only on peri-implant mucositis sites. \\
\hline
\end{tabular}




\subsubsection{Sample Size}

Sample size calculation (Alpha $=0.05$; Power $=95 \%$ ) for two independent study groups and a continuous primary endpoint required 26 total participants, of which 13 belonged to the trial group and 13 belonged to the placebo group.

A total of 26 patients were visited before the beginning of the study, and all of them agreed to participate and completed the study. Concerning the variable Probing Depth, an expected mean of $4.6 \mathrm{~mm}$ was hypothesized, with a standard deviation of 0.56 . The expected difference between the means was supposed to be 0.8 ; therefore, 13 patients were requested for each group [23].

\subsubsection{Randomization and Blinding}

By means of a block randomization table, the data analyst provided a randomization sequence, considering a permuted block of 13 participants. An operator enrolled the participants and executed the professional oral procedures. On the basis of previously prepared sequentially numbered, opaque, sealed envelopes (SNOSE) [24], an assistant assigned each participant to the respective group and had the task of setting the device to administer ozonized water for patients belonging to Group 1 (trial group) and pure water to Group 2 (control group). Another blind operator administered the treatment to the patients and measured the outcomes. Neither this latter operator nor the patients were aware of the treatment administered considering that no differences occurred between the two as regards the taste and the color. Even the data analyst was blinded for the allocation.

\subsubsection{Statistical Methods}

Data were submitted to statistical analysis with $\mathrm{R}$ Software ${ }^{\circledR}$ ( $\mathrm{R}$ version 3.1.3, $\mathrm{R}$ Development Core Team, R Foundation for Statistical Computing, Wien, Austria). For each group and variable, descriptive statistics (mean and standard deviation) were calculated. PPD was calculated in millimeters; BOP and PI were calculated in percentages; BS was calculated with the relative score. Data normality was calculated using the KolmogorovSmirnov test. For each variable, inferential comparisons among groups were performed using ANOVA with post hoc Tukey tests.

Significance was predetermined for $p<0.05$ for all the tests performed.

\section{Results}

\subsection{Baseline Characteristics}

The trial group was made of seven males and six females with a mean age of 59.9 y.o. (standard deviation 7.9 y.o.), whereas the placebo group of five males and eight females had a mean age of 62.3 y.o. (standard deviation 9 y.o.).

The flow-chart of the study is shown in Figure 1. 


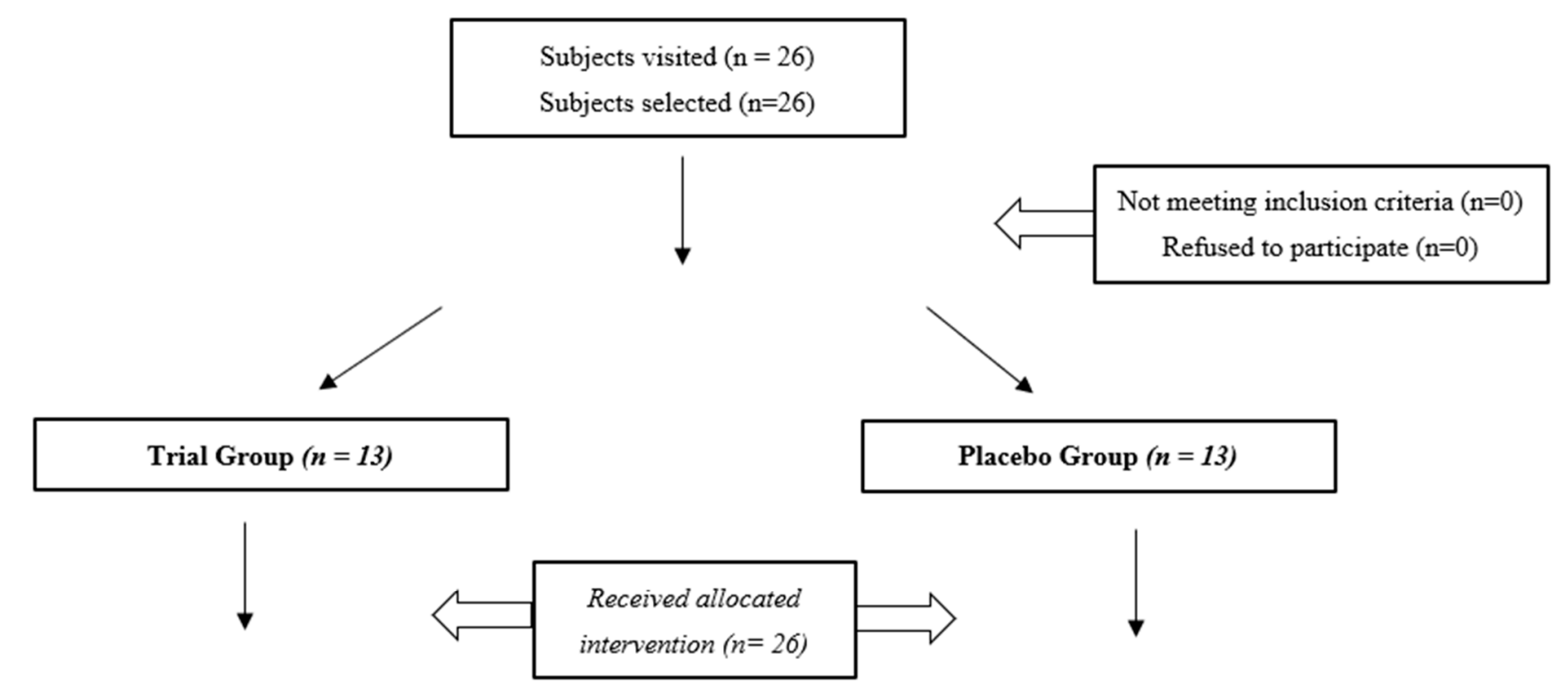

\section{Ozonized water administration on} peri-implant mucositis sites

Pure water administration on peri-implant mucositis sites

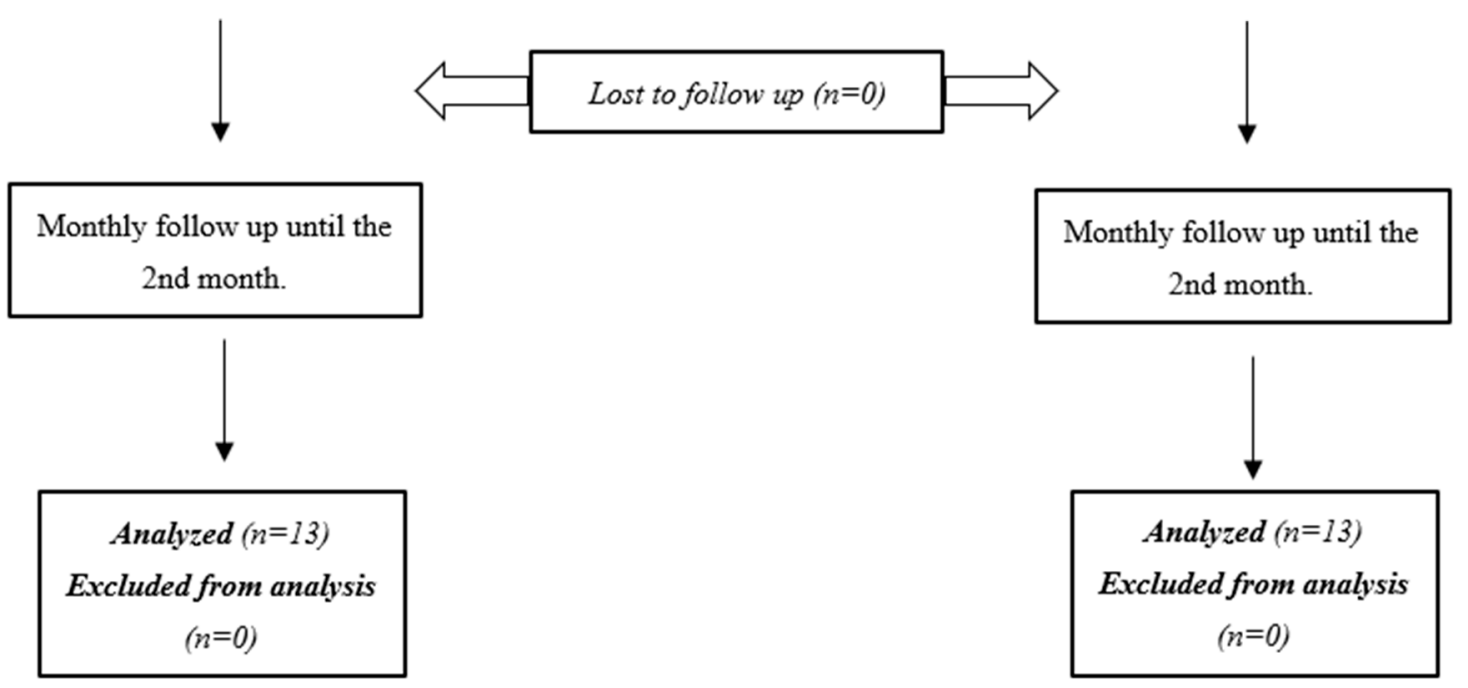

Figure 1. Flow-chart of the study: the figure shows the process of selection, random allocation and follow up of the participants to the study.

\subsection{Probing Pocket Depth (PPD)}

The PPD significantly and progressively decreased after baseline in Group 1, whereas no difference was found in the placebo group. No significant intergroup differences were assessed at baseline and at T1 time frames, while a significant difference was present between the groups at T2. The results are shown in Table 2 and Figure 2. 
Table 2. Descriptive statistics of Probing Pocket Depth measurements (PPD).

\begin{tabular}{|c|c|c|c|c|c|c|c|c|}
\hline Group & Time & Mean & St Dev & Min & Median & Max & $\begin{array}{c}\text { Intragroup } \\
\text { Differences * }\end{array}$ & $\begin{array}{c}\text { Intergroup } \\
\text { Differences }\end{array}$ \\
\hline \multirow[t]{3}{*}{ Trial Group } & T0 & 4.65 & 0.57 & 4.00 & 4.70 & 5.71 & $\mathrm{~A}$ & T0: ns \\
\hline & $\mathrm{T} 1$ & 4.14 & 0.87 & 3.00 & 4.00 & 5.82 & B & T1: ns \\
\hline & $\mathrm{T} 2$ & 3.84 & 0.67 & 3.00 & 3.63 & 5.24 & $\mathrm{C}$ & $\mathrm{T} 2: p<0.05$ \\
\hline \multirow[t]{3}{*}{ Placebo Group } & T0 & 4.67 & 0.75 & 4.00 & 4.50 & 6.33 & A & \\
\hline & $\mathrm{T} 1$ & 4.55 & 0.66 & 3.33 & 4.75 & 5.54 & A & \\
\hline & $\mathrm{T} 2$ & 4.66 & 0.96 & 3.25 & 4.34 & 6.91 & A & \\
\hline
\end{tabular}

* Different letters show statistically significant differences among the time frames $(p<0.05) ;{ }^{\dagger} \mathrm{ns}=$ not significant.

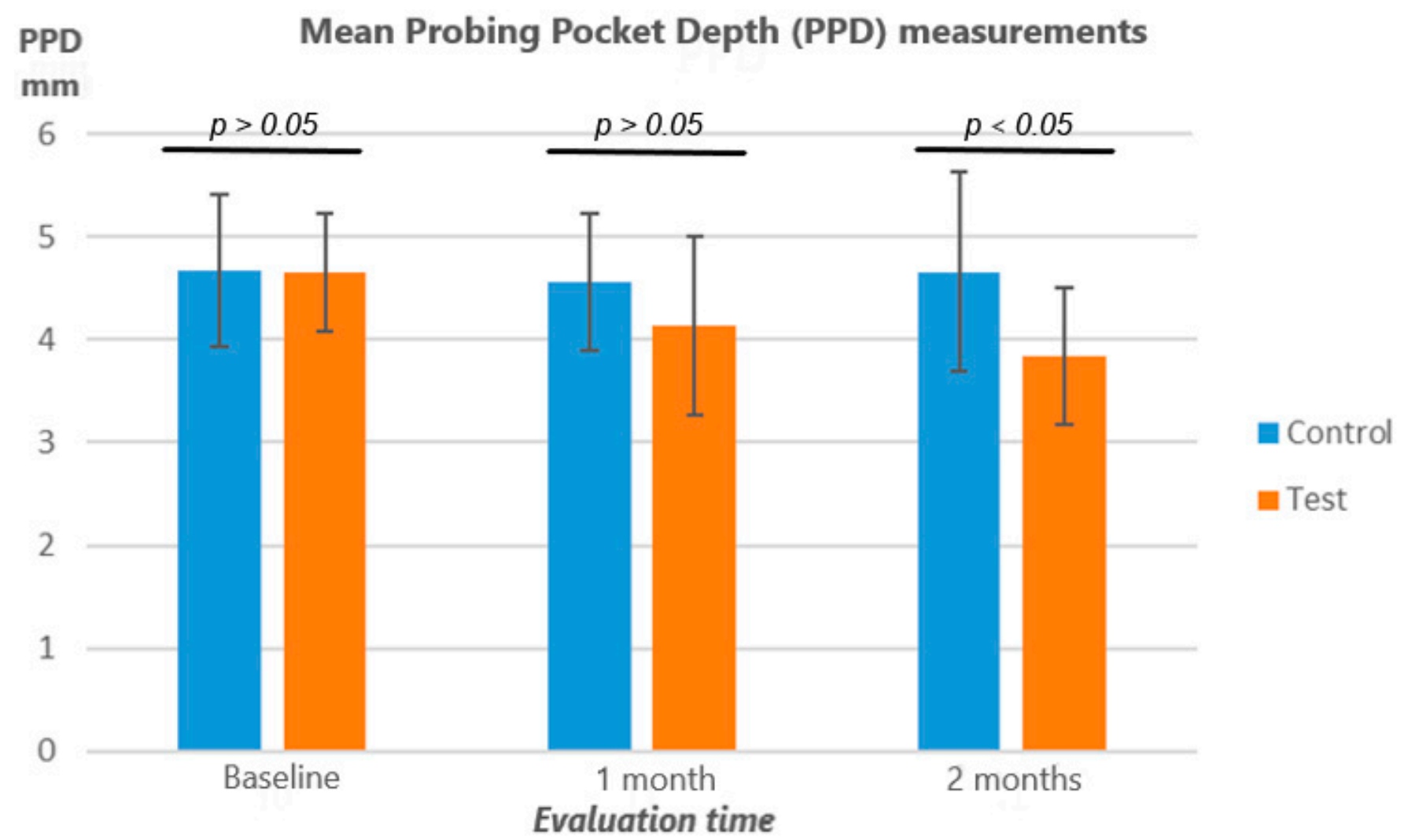

Figure 2. Probing Pocket Depth measurements $(\mathrm{mm})$ : the figure shows the absence of intergroup differences at all the evaluation times $(p>0.05)$, except at T2 $(p<0.05)$. As to intragroup differences, a progressive significant reduction in the index was assessed in the trial group but not in the control one.

\subsection{Plaque Index (PI\%)}

PI significantly decreased after baseline in Group 1 at $\mathrm{T} 1$, whereas no difference was found in the range T1-T2. In Group 2, no significant differences were found between the time frames. No significant intergroup differences were assessed at any time frame. The results are shown in Table 3 and Figure 3. 
Table 3. Descriptive statistics of Plaque Index measurements (PI\%).

\begin{tabular}{ccccccccc}
\hline Group & Time & Mean & St Dev & Min & Median & Max & $\begin{array}{c}\text { Intragroup } \\
\text { Differences * }\end{array}$ & $\begin{array}{c}\text { Intergroup } \\
\text { Differences }\end{array}$ \\
\hline Trial Group & T0 & 73.65 & 25.67 & 25.00 & 75.00 & 100.00 & A & T0: ns \\
& T1 & 56.71 & 21.02 & 25.00 & 50.00 & 100.00 & T1: ns & T2: ns \\
Placebo Group & T2 & 49.68 & 28.13 & 0.00 & 50.00 & 100.00 & B & B \\
& T0 & 54.62 & 27.38 & 22.50 & 50.00 & 100.00 & & \\
& T1 & 54.31 & 23.86 & 25.00 & 50.00 & 87.50 & B & \\
\hline
\end{tabular}

${ }^{*}$ Different letters show statistically significant differences among the time frames $(p<0.05) ;{ }^{\dagger} \mathrm{ns}=$ not significant.

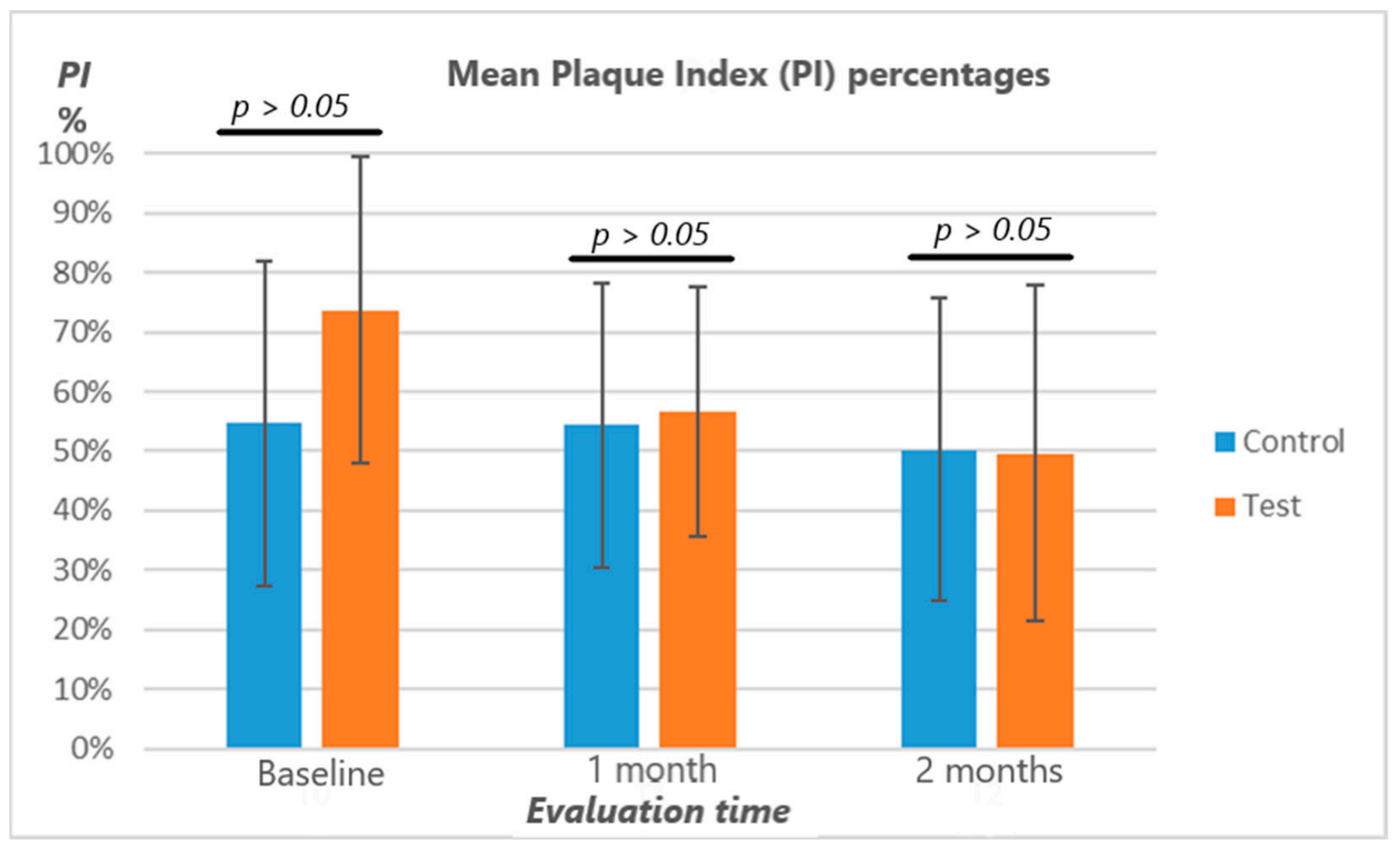

Figure 3. Plaque Index percentages (\%): the figure shows the absence of intergroup differences at all the evaluation times $(p>0.05)$. As to intragroup differences, a progressive significant reduction in the index was assessed in the trial group (not significant between T1-T2), but not in the control one.

\subsection{Bleeding on Probing (BOP)}

The percentage of BOP significantly decreased after baseline in Group 1 in the ranges T0-T1 and T1-T2. In Group 2, no significant difference was found between the time frames. No significant intergroup differences were assessed at any time frame. The results are shown in Table 4 and Figure 4. 
Table 4. Descriptive statistics of Bleeding on Probing measurements (BOP\%).

\begin{tabular}{ccccccccc}
\hline Group & Time & Mean & St Dev & Min & Median & Max & $\begin{array}{c}\text { Intragroup } \\
\text { Differences * }\end{array}$ & $\begin{array}{c}\text { Intergroup } \\
\text { Differences }\end{array}$ \\
\hline Trial Group & T0 & 61.96 & 26.69 & 16.67 & 63.33 & 100.00 & A & T0: ns \\
& T1 & 42.60 & 33.15 & 0.00 & 33.33 & 100.00 & T1: ns & T2: ns \\
Placebo Group & T2 & 29.55 & 31.43 & 0.00 & 29.17 & 100.00 & D & \\
& T0 & 50.14 & 25.43 & 16.67 & 50.00 & 100.00 & D & \\
& T1 & 53.46 & 26.10 & 16.67 & 50.00 & 100.00 & D & \\
\hline
\end{tabular}

${ }^{*}$ Different letters show statistically significant differences among the time frames $(p<0.05) ;{ }^{\dagger} \mathrm{ns}=$ not significant.

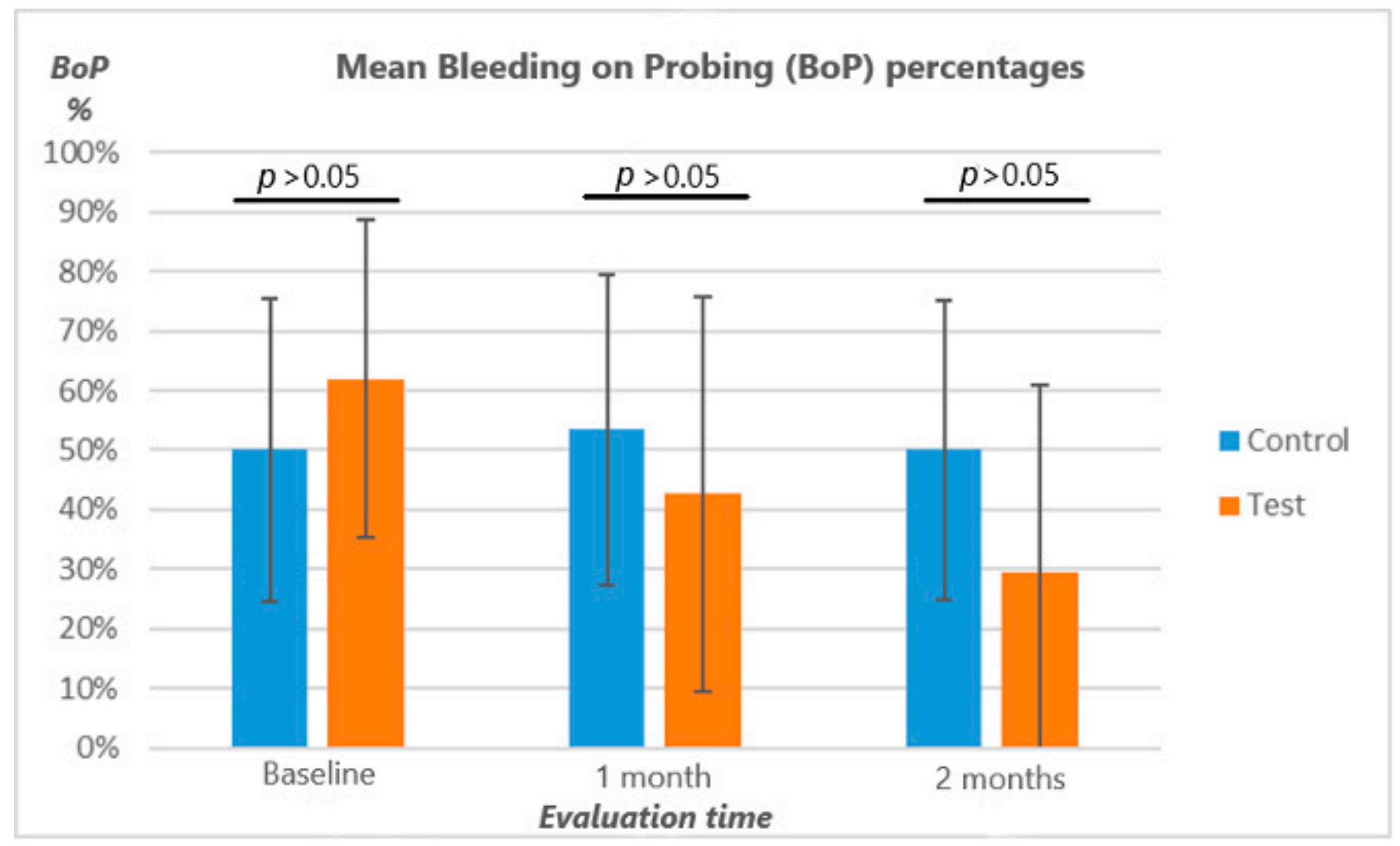

Figure 4. Bleeding on Probing percentages (\%): the figure shows the absence of intergroup differences at all the evaluation times $(p>0.05)$. As to intragroup differences, a progressive significant reduction in the index was assessed in the trial group but not in the control one.

\subsection{Bleeding Score}

The BS significantly decreased after baseline in Group 1 in the ranges T0-T1 and T1-T2. In Group 2, no significant difference was found between the time frames. No significant intergroup differences were assessed at any time frame. The results are shown in Table 5 and Figure 5. 
Table 5. Descriptive statistics of Bleeding Score measurements (BS).

\begin{tabular}{ccccccccc}
\hline Group & Time & Mean & St Dev & Min & Median & Max & $\begin{array}{c}\text { Intragroup } \\
\text { Differences * }\end{array}$ & $\begin{array}{c}\text { Intergroup } \\
\text { Differences }\end{array}$ \\
\hline Trial Group & T0 & 1.86 & 0.46 & 1.00 & 2.00 & 3.00 & A & T0: ns \\
& T1 & 1.16 & 0.89 & 0.00 & 1.00 & 3.00 & B & T1: ns \\
Placebo Group & T2 & 0.70 & 0.83 & 0.00 & 0.50 & 3.00 & D & \\
& T0 & 1.43 & 0.66 & 0.55 & 1.25 & 2.50 & D & \\
& T1 & 1.50 & 0.78 & 0.60 & 1.25 & 3.00 & D & \\
\hline
\end{tabular}

${ }^{*}$ Different letters show statistically significant differences among the time frames $(p<0.05) ;{ }^{\dagger} \mathrm{ns}=$ not significant.

\section{Mean Bleeding Score (BS)}

\section{BS}

$(0-3)$

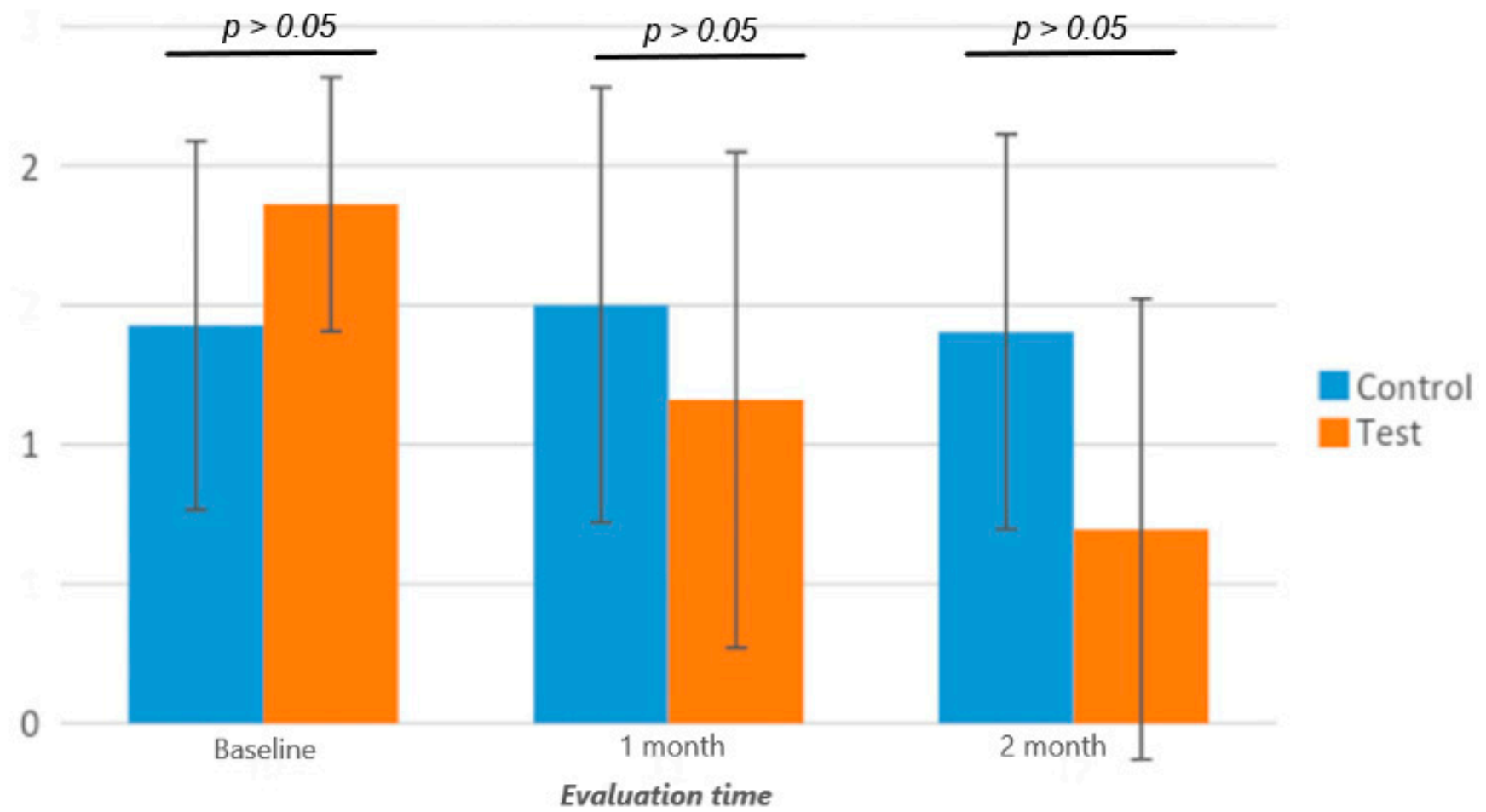

Figure 5. Bleeding Score (0-3): the figure shows the absence of intergroup differences at all the evaluation times $(p>0.05)$. As to intragroup differences, a progressive significant reduction in the index was assessed in the trial group but not in the control one.

\section{Discussion}

The assurance of correct oral hygiene procedures plays a key role for the long-term maintenance of implant sites, thus avoiding the development of peri-implant mucositis and eventually peri-implantitis, with the risk of implant failure. Several hygiene protocols have been proposed, all sharing the common goal of disrupting the subgingival biofilm while avoiding the alteration of the implant surface [25]; these treatment modalities include mechanical debridement [26], the administration of chlorhexidine [27], and air polishing with glycine or bicarbonate powder [28]. Despite this quite wide range of therapeutic modalities, until now, none seemed to meet all the requirements which include the cleaning efficacy, the biocompatibility, and a low risk of alterations of the implant's surface.

Based on this consideration, the aim of the present report has been that of evaluating the efficacy of ozone therapy for the treatment of peri-implant mucositis. Several clinical conditions are currently being addressed by means of ozone, due to its recognized wide 
properties. However, the possible role for the maintenance of oral implants undergoing a reversible inflammatory process seems to be poorly explored in the literature so far.

The null hypotheses of this study were rejected. As regards the intragroup comparisons, we can state that the application of ozonized water in the trial group succeeded in reducing all the clinical indexes tested, with a progressive decrease from baseline to the subsequent two months (except when considering the period T1-T2 for the Plaque Index). Conversely, no significant difference occurred for the control group. Therefore, ozone has reported a beneficial effect on the peri-implant status, whereas pure water did not cause any significant variation, as expected. Despite this apparent positive outcome for the ozonized water, the evidence obtained from the subsequent intergroup comparisons seems to point towards a different direction. No significant differences were assessed comparing each respective time frame for the two groups, except for PPD at T2. Only in this latter case, in fact, did ozonized water manage to cause a more significant clinical improvement with respect to the pure water. Therefore, on the basis of the present results, ozonized water improved all the clinical indexes tested, whereas the pure water had no effect on the peri-implant status, but, except for the better outcome reported for PPD at the 2-month time, any relevant action has resulted in this study for ozone therapy on the peri-implant sites affected by mucositis. However, it is important to consider that for PPD measurements the presence of statistically significant differences does not directly correspond to important differences at a clinical level. In fact, PPD, like the other indexes considered, results in being a surrogate endpoint whose improvement might not coincide with more "patient-centered" ones (e.g., the long-term survival rate of the implant in the mouth) which should be evaluated in future studies.

Taking a glance at the literature, we can observe that little research has been conducted to date on the treatment of peri-implant mucositis using ozone therapy. McKenna et al. [29] conducted a randomized controlled trial to test the effect of subgingival applications of ozone and/or hydrogen peroxide on peri-implant mucositis. The following treatments were randomly applied for $60 \mathrm{~s}$ (as in our study) to the implant sites on days 0,7 and 14: (1), $\mathrm{O}_{2}$ and $0.9 \% \mathrm{NaCl}$ (control group), (2) $\mathrm{O}_{2}$ and $\mathrm{H}_{2} \mathrm{O}_{2}(3 \%)$, (3) $\mathrm{O}_{3}$ and $0.9 \% \mathrm{NaCl}$, and (4) $\mathrm{O}_{3}$ and $\mathrm{H}_{2} \mathrm{O}_{2}(3 \%)$. On days $0,7,14$ and 21, both plaque, gingival, and bleeding indices were registered. The authors found that both treatments including ozone produced optimal gingival health scores and equally controlled bleeding more effectively than the other experimental treatment.

The use of ozone has been mostly evaluated as an adjunct to the surgical treatment of peri-implantitis, the irreversible form of inflammation occurring on implant sites. In the study by Isler et al., [30] 41 patients were randomly allocated to an implant surface decontamination by means of sterile saline with additional ozone gas or the control group with sterile saline alone. According to the authors, the additional use of ozone for Scaling and Root Planing (SRP) showed both clinical and radiographic significant improvements.

Despite our results disagreeing with these conclusions, no direct comparison can be carried out because of the different methodologies considered. For instance, the latter study considered peri-implantitis, instead of peri-implant mucositis, and additionally, a different formulation of ozone was used, like in the previous trial mentioned (gaseous ozone instead of the ozonized water used in our current research).

The results obtained by our group show a certain efficacy of ozonized water if considered alone, but the absence of significant differences if compared to the control treatment allow us to draw no firm conclusions, especially because of the presence of some limitations in the study. For example, the type of implant, the time since its insertion, and the eventual intake of anti-inflammatory/antibiotics among participants were not considered, thus affecting the homogeneity of the two random groups at baseline. Additionally, the absence of intra-rater reliability (measured by the Cohen's kappa coefficient) might hide a measurement bias, especially for PPD considering the highly variability between operators when using a probe (e.g., different pression used, etc.), thus affecting the reliability of clinical measurements, resulting in underestimated or overestimated values. Moreover, 
the use of PPD as a clinical parameter to perform sample size calculation might lead to a wider trial with more conclusive results. Therefore, future research deserves to be conducted with the aim to clearly define the efficacy of ozonized water for the management of peri-implant mucositis, along with other devices for the domiciliary treatment of this condition [31]. In particular, subsequent randomized clinical trials should compare its action with that of treatments considered as positive controls (such as chlorhexidine and glycine or bicarbonate powder) [25]. A longer follow up should be considered in order to evaluate the long-term benefit of ozone. Finally, microbiological tests should also be addressed to fully understand which oral hygiene protocol guarantees the major efficacy towards peri-implant mucositis.

\section{Conclusions}

According to the results of this study, the application of ozonized water on periimplant mucositis sites has significantly reduced all the clinical indexes, with a progressive improvement from baseline to the subsequent assessments at 1 month and 2 months, except for the Plaque Index, which only improved at 1 month without a further subsequent significant reduction. Conversely, no significant differences occurred within the control group exposed to pure water administration. Despite the fact that no significant intergroup differences were generally detected between the ozone and the control treatment, ozone therapy deserves to be further evaluated as a means to tackle the reversible inflammation of peri-implant sites, also avoiding an eventual progression towards peri-implantitis.

Author Contributions: Conceptualization, A.B. and A.S.; methodology, A.S. and A.B.; software, A.S.; validation, S.G. and M.P.; formal analysis, A.S.; investigation, G.L. and A.B.; resources, A.B.; data curation, G.L. and A.S.; writing-original draft preparation, S.G. and M.P.; writing-review and editing, A.S., S.G. and M.P.; visualization, A.S. and A.B.; supervision, A.S.; project administration, A.B. All authors have read and agreed to the published version of the manuscript.

Funding: This research received no external funding.

Institutional Review Board Statement: The study was conducted according to the guidelines of the Declaration of Helsinki and approved by the Internal Review Board of the Unit of Orthodontics and Pediatric Dentistry, Section of Dentistry, University of Pavia, Pavia, Italy (registration number: 2021-0203) and registered on Clinicaltrials.gov (NCT number: NCT04845087).

Informed Consent Statement: Informed consent was obtained from all subjects involved in the study.

Data Availability Statement: Data are available upon reasonable request to the corresponding authors.

Conflicts of Interest: The authors declare no conflict of interest.

\section{References}

1. Sechi, L.A.; Lezcano, I.; Nunez, N.; Espim, M.; Duprè, I.; Pinna, A.; Molicotti, P.; Fadda, G.; Zanetti, S. Antibacterial activity of ozonized sunflower oil (Oleozon). J. Appl. Microbiol. 2001, 90, 279-284. [CrossRef]

2. Lezcano, I.; Nuñez, N.; Espino, M.; Gómez, M. Antibacterial activity of ozonized sunflower oil, oleozon, against Staphylococcus aureus and Staphylococcus epidermidis. Ozone Sci. Eng. 2000, 22, 207-214. [CrossRef]

3. Mascarenhas, L.A.B.; Oliveira, F.O.; da Silva, E.S.; dos Santos, L.M.C.; de Alencar Pereira Rodrigues, L.; Neves, P.R.F.; Santos, A.Á.B.; Moreira, G.A.F.; Lobato, G.M.; Nascimento, C.; et al. Technological Advances in Ozone and Ozonized Water Spray Disinfection Devices. Appl. Sci. 2021, 11, 3081. [CrossRef]

4. Giuroiu, C.L.; Andrian, S.; Stoleriu, S.; Scurtu, M.; Țănculescu, O.; Poroch, V.; Sălceanu, M. The Combination of Diode Laser and Ozonated Water in the Treatment of Complicated Pulp Gangrene. Appl. Sci. 2020, 10, 4203. [CrossRef]

5. Silva, V.; Peirone, C.; Capita, R.; Alonso-Calleja, C.; Marques-Magallanes, J.A.; Pires, I.; Maltez, L.; Pereira, J.E.; Igrejas, G.; Poeta, P. Topical Application of Ozonated Oils for the Treatment of MRSA Skin Infection in an Animal Model of Infected Ulcer. Biology 2021, 10, 372. [CrossRef] [PubMed]

6. Di Mauro, R.; Cantarella, G.; Bernardini, R.; Di Rosa, M.; Barbagallo, I.; Distefano, A.; Longhitano, L.; Vicario, N.; Nicolosi, D.; Lazzarino, G.; et al. The Biochemical and Pharmacological Properties of Ozone: The Smell of Protection in Acute and Chronic Diseases. Int. J. Mol. Sci. 2019, 20, 634. [CrossRef] [PubMed]

7. Monzillo, V.; Lallitto, F.; Russo, A.; Poggio, C.; Scribante, A.; Arciola, C.R.; Bertuccio, F.R.; Colombo, M. Ozonized Gel Against Four Candida Species: A Pilot Study and Clinical Perspectives. Materials 2020, 13, 1731. [CrossRef] [PubMed] 
8. Gallo, S.; Scribante, A. Ozone therapy in dentistry: From traditional applications towards innovative ones. A review of the literature. IOP Conf. Ser. Earth Environ. Sci. 2021, 707, 012001. [CrossRef]

9. Suh, Y.; Shrey, P.; Re, K.; Gandhi, J.; Joshi, G. Clinical utility of ozone therapy in dental and oral medicine. Med. Gas. Res. 2019, 9, 163-167. [PubMed]

10. Colombo, M.; Gallo, S.; Garofoli, A.; Poggio, C.; Arciola, C.R.; Scribante, A. Ozone Gel in Chronic Periodontal Disease: A Randomized Clinical Trial on the Anti-Inflammatory Effects of Ozone Application. Biology 2021, 10, 625. [CrossRef]

11. El Hadary, A.A.; Yassin, H.H.; Mekhemer, S.T.; Holmes, J.C.; Grootveld, M. Evaluation of the effect of ozonated plant oils on the quality of osseointegration of dental implants under the influence of Cyclosporin A an in vivo study. J. Oral Implantol. 2011, 37, 247-257. [CrossRef]

12. Yücesoy, T.; Seker, E.D.; Cenkc1, E.; Yay, A.; Alkan, A. Histologic and Biomechanical Evaluation of Osseointegrated Miniscrew Implants Treated with Ozone Therapy and Photobiomodulation at Different Loading Times. Int. J. Oral. Maxillofac. Implants 2019, 34, 1337-1345. [CrossRef] [PubMed]

13. Karaca, I.R.; Ergun, G.; Ozturk, D.N. Is Low-level laser therapy and gaseous ozone application effective on osseointegration of immediately loaded implants? Niger J. Clin. Pract. 2018, 21, 703-710. [CrossRef]

14. Shekhar, A.; Srivastava, S.; Kumar Bhati, L.; Chaturvedi, A.; Singh, S.; Agarwal, B.; Arora, K. An evaluation of the effect of ozone therapy on tissues surrounding dental implants. Int. Immunopharmacol. 2021, 96, 107588. [CrossRef] [PubMed]

15. Butera, A.; Gallo, S.; Maiorani, C.; Molino, D.; Chiesa, A.; Preda, C.; Esposito, F.; Scribante, A. Probiotic Alternative to Chlorhexidine in Periodontal Therapy: Evaluation of Clinical and Microbiological Parameters. Microorganisms 2020, 9, 69. [CrossRef]

16. Könönen, E.; Gursoy, M.; Gursoy, U.K. Periodontitis: A Multifaceted Disease of Tooth-Supporting Tissues. J. Clin. Med. 2019, 8, 1135. [CrossRef]

17. Roos-Jansaker, A.M.; Lindahl, C.; Renvert, H.; Renvert, S. Nine- to fourteen-year follow-up of implant treatment. Part I: Implant loss and associations to various factors. J. Clin. Periodontol. 2006, 33, 283-289. [CrossRef]

18. Berglundh, T.; Armitage, G.; Araujo, M.G.; Avila-Ortiz, G.; Blanco, J.; Camargo, P.M.; Chen, S.; Cochran, D.; Derks, J.; Figuero, E.; et al. Peri-implant dis-eases and conditions: Consensus report of workgroup 4 of the 2017 World Workshop on the Classification of Periodontal and Peri-Implant Diseases and Conditions. J. Clin. Periodontol. 2018, 45, S286-S291. [CrossRef] [PubMed]

19. Heitz-Mayfield, L.J.A.; Salvi, G.E. Peri-implant mucositis. J. Clin. Periodontol. 2018, 45, S237-S245. [CrossRef] [PubMed]

20. Ericsson, I.; Berglundh, T.; Marinello, C.; Liljenberg, B.; Lindhe, J. Long-standing plaque and gingivitis at implants and teeth in thedog. Clin. Oral Implants Res. 1992, 3, 99-103. [CrossRef]

21. Khammissa, R.A.; Feller, L.; Meyerov, R.; Lemmer, J. Peri-implant mucositis and peri-implantitis: Clinical and histopathological characteristics and treatment. S. Afr. Dent. J. 2012, 67, 122, 124-126.

22. Aimetti, M.; Mariani, G.M.; Ferrarotti, F.; Ercoli, E.; Liu, C.C.; Romano, F. Adjunctive efficacy of diode laser in the treatment of peri-implant mucositis with mechanical therapy: A randomized clinical trial. Clin. Oral Implants Res. 2019, 30, 429-438. [CrossRef] [PubMed]

23. Ji, Y.J.; Tang, Z.H.; Wang, R.; Cao, J.; Cao, C.F.; Jin, L.J. Effect of glycine powder air-polishing as an adjunct in the treatment of peri-implant mucositis: A pilot clinical trial. Clin. Oral Implants Res. 2014, 25, 683-689. [CrossRef] [PubMed]

24. Schulz, K.F.; Chalmers, I.; Grimes, D.A.; Altman, D.G. Assessing the quality of randomization from reports of controlled trials published in obstetrics and gynecology journals. JAMA 1994, 272, 125-128. [CrossRef]

25. Ermetici, M.; Segù, M.; Butera, A. Comparison to the scanning electron microscope of professional dental hygiene methods on metal-free layered structures and metal-free monolithic structures processed by different polymerization cycles. Minerva Stomatol. 2014, 63, 189-202. [PubMed]

26. Sahm, N.; Becker, J.; Santel, T.; Schwarz, F. Non-surgical treatment of peri-implantitis using an air-abrasive device or mechanical debridement and local application of chlorhexidine: A prospective, randomized, controlled clinical study. J. Clin. Periodontol. 2011, 38, 872-878. [CrossRef]

27. De Araujo, N.; Capelas, C.; Alves, A.; Almeida, T.; Carvalho, R.; Antunes, E.; Oliveira, D.; Cardador, A.; Maló, P. Non-surgical treatment of peri-implant pathology. Int. J. Dent. Hygiene 2006, 4, 84-90. [CrossRef]

28. Louropoulou, A.; Slot, D.E.; van der Weijden, F.A. Titanium surface alterations following the use of different mechanical instruments: A systematic review. Clin. Oral Implants Res. 2012, 23, 643-658. [CrossRef] [PubMed]

29. McKenna, D.F.; Borzabadi-Farahani, A.; Lynch, E. The effect of subgingival ozone and/or hydrogen peroxide on the development of peri-implant mucositis: A double-blind randomized controlled trial. Int. J. Oral Maxillofac. Implants 2013, 28, 1483-1489. [CrossRef]

30. Isler, S.C.; Unsal, B.; Soysal, F.; Ozcan, G.; Peker, E.; Karaca, I.R. The effects of ozone therapy as an adjunct to the surgical treatment of peri-implantitis. J. Periodontal Implant Sci. 2018, 48, 136-151. [CrossRef]

31. Preda, C.; Butera, A.; Pelle, S.; Pautasso, E.; Chiesa, A.; Esposito, F.; Oldoini, G.; Scribante, A.; Genovesi, A.M.; Cosola, S. The Efficacy of Powered Oscillating Heads vs. Powered Sonic Action Heads Toothbrushes to Maintain Periodontal and Peri-Implant Health: A Narrative Review. Int. J. Environ. Res. Public. Health 2021, 18, 1468. [CrossRef] [PubMed] 